\title{
Obtenção de vazão de diluição de efluentes utilizando o modelo de qualidade de água QUAL-UFMG
}

O modelo vigente de desenvolvimento socioeconômico, associado ao crescimento populacional acelerado e a necessidade de atendimento às diversas atividades humanas têm evidenciado um panorama complexo de poluição nos corpos hídricos, causando consequências diretas na capacidade de diluição e de autodepuração dos rios. A implantação de sistemas de suporte a decisão e modelagens de qualidade da água tornam-se essenciais para se alcançar uma eficiente gestão das águas e articulação dos instrumentos da Política Nacional de Recursos Hídricos. Assim, o objetivo principal deste trabalho foi a obtenção das vazões de diluição de efluentes do rio Piracicaba utilizando o modelo de qualidade da água QUAL-UFMG. Para isso, foi realizado o ajuste e a calibração do modelo através de dados hidrológicos e de qualidade da água provenientes das estações fluviométricas. A partir dos resultados da modelagem constatou-se que o modelo conseguiu mostrar a realidade do rio estudado. A simulação hipotética efetuada de instalação de sistemas de tratamento de efluentes domésticos para alguns lançamentos diretamente no rio Piracicaba demonstrou um decréscimo de $36,96 \%$ na concentração de DBO. A mudança nas classes de enquadramento resultou em variações de até $79,83 \%$ nas vazões de diluição. A classe de enquadramento exerce significativa influência nas vazões de diluição, com aumento dos valores consoantes ao nível e restrição, ou seja, cada vez que diminui a DBO permitida no corpo d'água, a vazão de diluição eleva-se. É interessante ressaltar que de acordo com as condições calculadas de vazão de diluição, a consideração dos lançamentos em todo o corpo hídricos é de extrema importância para a determinação das vazões disponíveis e indisponíveis e consequente disponibilidade hídrica.

Palavras-chave: Modelagem de Qualidade da Água; QUAL-UFMG; Diluição.

\section{Obtaining effluent dilution flow using the QUAL-UFMG water quality model}

The supervised model of socioeconomic development, associated with accelerated population growth and the need to attend to various human activities evidenced in a complex panorama of pollution in water bodies, which directly affects the dilution capacity and self-purification of rivers. The implementation of decision support systems and water quality models is essential for efficient water management and articulation of the National Water Resources Policy instruments. Thus, the main objective of this work is to analyze the dilution capacity using the QUAL-UFMG water quality model in a case study in the Piracicaba River. For this, the model was adjusted and calibrated using hydrological and water quality data from fluviometric stations. From the results of the modeling it was possible to make a diagnosis of the basin and after the application of the model it was found that it was able to represent well the reality of the river studied. The hypothetical simulation considering the installation of domestic effluent treatment systems for some discharges directly into the Piracicaba River showed a $36.96 \%$ decrease in biochemical oxygen demand concentration. The change in the framing classes resulted in variations of up to $79.83 \%$ in the dilution flows. The framing class has a significant influence on the dilution flows, with an increase in the consonant values for level and restriction, that is, each time the permitted biochemical oxygen demand concentration in the water body decreases, the dilution flow increases. It is interesting to note that according to the calculated dilution flow conditions, the consideration of previous releases is of extreme importance for the determination of available and unavailable flows and consequent water availability.

Keywords: Water Quality Modeling; QUAL-UFMG; Dilution.

Topic: Tecnologia, Modelagem e Geoprocessamento

Reviewed anonymously in the process of blind peer.

Viviane Ramos de Carvalho (i)

Universidade Federal de Itajubá, Brasil

http://lattes.cnpq.br/2884693850454376

http://orcid.org/0000-0002-3646-1939

vivianerc.amb@gmail.com

José Augusto Costa Gonçalves (iD)

Universidade Federal de Itajubá, Brasil

http://lattes.cnpq.br/1406590880915046

http://orcid.org/0000-0003-1659-0896

jaucosta@gmail.com

Eduardo de Aguiar do Couto (iD)

Universidade Federal de Itajubá, Brasil

http://lattes.cnpq.br/6707163305986412

http://orcid.org/0000-0002-2976-9302

eduardocouto@unifei.edu.br

DOI: 10.6008/CBPC2179-6858.2021.004.0056
Received: 02/04/2021

Approved: 29/04/2021

\section{Referencing this:}

CARVALHO, V. R.; GONÇALVES, J. A. C.; COUTO, E. A.. Obtenção de vazão de diluição de efluentes utilizando o modelo de qualidade de água QUAL-UFMG. Revista Ibero Americana de Ciências Ambientais, v.12, n.4, p.737-753, 2021. DOI: http://doi.org/10.6008/CBPC2179$\underline{6858.2021 .004 .0056}$ 


\section{INTRODUÇÃO}

A Política Nacional de Recursos Hídricos (PNRH), instituída pela Lei n. 9.433 de 8 de janeiro de 1997, no artigo 2, inciso I, mostra que entre os objetivos da referida lei está "assegurar à atual e às futuras gerações a necessária disponibilidade de água, em padrões de qualidade adequados aos respectivos usos" (BRASIL, 1997; ANA, 2005). Mesmo diante da consciência de que água é um recurso indispensável, há permanentes ameaças à quantidade e qualidade da água doce disponível no planeta (ANA, 2007; REBOUÇAS et al., 1999).

A utilização da modelagem da qualidade de água pode ser considerada como uma importante ferramenta para subsidiar a gestão dos recursos hídricos visando o seu uso múltiplo (KNAPIK, 2009; ABBASPOUR et al., 2015). A modelagem da qualidade das águas possibilita uma abordagem holística sobre os processos que se desenvolvem em um ecossistema aquático, além de prever as reações e estímulos externos, estimando a capacidade de assimilação de efluentes (MENEZES et al., 2016; PIMPUNCHAT et al., 2009).

A capacidade de diluição e de autodepuração de um rio é função de uma série de fatores que variam de um corpo hídrico para outro, e esta capacidade é que define o quanto de efluente - ou matéria orgânica - poderá ser lançado no corpo receptor (GAZZAZ et al., 2012; COX, 2003; CHAPRA, 1997). Essa capacidade é limitada e depende das características do corpo hídrico, da quantidade e natureza da matéria orgânica presente no mesmo, dos microrganismos que promovem a transformação dessa matéria orgânica em compostos mais simples, e das condições ambientais (KANNEL et al., 2011; BRAGA JUNIOR et al., 2002).

A aplicação de modelos matemáticos de qualidade da água possibilita avaliar os impactos do lançamento das cargas poluidoras e analisar possíveis cenários para tomadas de medidas de controle ambiental (EPA, 1987). Ao longo do tempo, vários modelos foram utilizados desde o desenvolvimento do pioneiro modelo clássico de Streeter e Phelps, em 1925, desenvolvido para o Rio Ohio. Na evolução dos modelos, com relação ao grau de complexidade e o número de variáveis modeladas, diversos modelos foram apresentados, como QUAL2E (CHAPRA, 1997), QUAL2K (CHAPRA et al., 2006), AQUASIM (REICHERT, 1998), GESCAL (PAREDES et al., 2010).

Von Sperling (2014) criou um modelo simplificado do QUAL2E e QUAL2K, originariamente desenvolvidos pela US Environmental Protection Agency (USEPA), e denominado de QUAL-UFMG. Este modelo simplificado, não leva em consideração a influência de algas e suas inter-relações, considerando que são importantes em ambientes lênticos. O modelo tem grande aceitação em decorrência da praticidade e ser de fácil manuseio. No Brasil foi utilizado por (PEREIRA et al., 2011; SILVA et al., 2011; AMORIM JUNIOR et al., 2011; GUEDES, 2009; BÁRBARA, 2006; BALDOCHI, 2002; PEREIRA et al., 2005; FAN et al., 2009; KNAPIK, 2009).

Este trabalho tem por objetivo principal a obtenção das vazões de diluição de efluentes e as vazões disponíveis, comparando-as com as classes de enquadramento do rio Piracicaba, utilizando o modelo de qualidade da água QUAL-UFMG, a partir dos ajustamentos dos coeficientes que compõe o modelo, simulando cenários hipotéticos de instalação de sistemas de tratamento de efluentes domésticos que lançariam 
diretamente no rio.

\section{MATERIAIS E MÉTODOS}

\section{Área de estudo}

A bacia hidrográfica do rio Piracicaba, Figura 1, está localizada no leste do estado de Minas Gerais. A bacia está compreendida entre os meridianos de 42 o 30' e 43노' de longitude oeste do meridiano de Greenwich e entre os paralelos de 1915’ e 2015’ de latitude sul. O Rio Piracicaba nasce no município de Ouro Preto, a 1680 m de altitude, seguindo na direção leste por 241 km, até desaguar no Rio Doce na área urbana da cidade de Ipatinga, a uma altitude de 210 m. É composta pelas sub-bacias dos rios Conceição, São João, Peixe, Santa Bárbara, Maquiné, Una, Prata. A bacia possui uma área de 5685,86 $\mathrm{km}^{2}$ e é formada por 21 municípios.

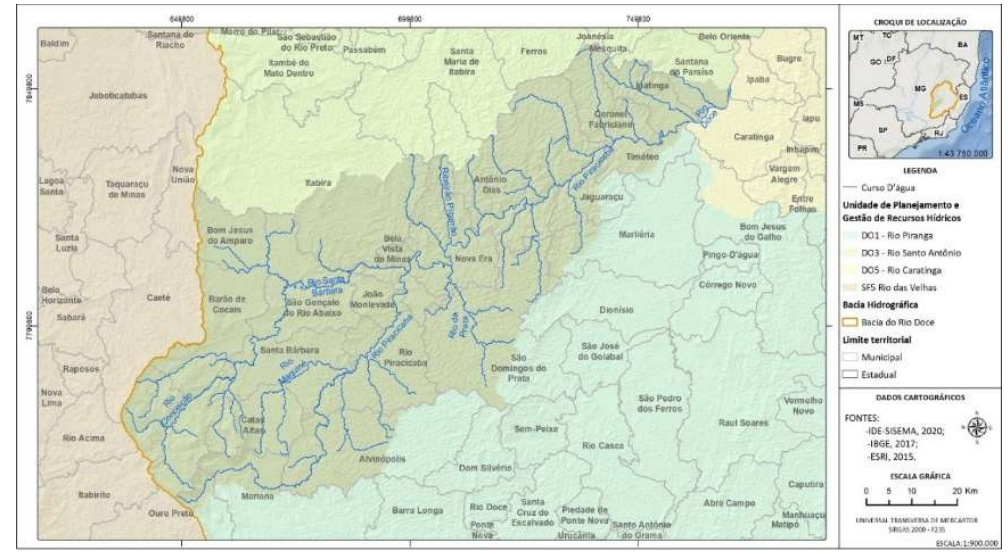

Figura 1: Mapa de localização da área de estudo. Fonte: Modificado de FEAM (2012).

\section{Equação de mistura em lançamentos pontuais}

A equação da mistura é uma média ponderada das concentrações com as respectivas vazões dos dois componentes que se misturam. A concentração de um constituinte qualquer (OD, DBO, N, P, coliformes, etc.) pode ser obtida por meio da Equação 1:

$$
C_{0}=\frac{Q_{r} C_{r}+Q_{e} C_{e}}{Q_{r}+Q_{e}}
$$

$C_{0}=$ concentração do constituinte na mistura $\left(\mathrm{mg} / \mathrm{L} \mathrm{ou} \mathrm{g} / \mathrm{m}^{3}\right)$

$C_{r}=$ concentração do constituinte no componente 1 (ex: rio, a montante do ponto de mistura $\left(\mathrm{mg} / \mathrm{L} \mathrm{ou} \mathrm{g} / \mathrm{m}^{3}\right)$ $C_{e}=$ concentração do constituinte no componente 2 (ex: esgoto, rio afluente), imediatamente a montante do ponto de mistura $\left(\mathrm{mg} / \mathrm{L}\right.$ ou $\left.\mathrm{g} / \mathrm{m}^{3}\right)$ $Q_{r}=$ vazão do compartimento $1\left(\mathrm{~L} / \mathrm{s}\right.$ ou $\left.\mathrm{m}^{3} / \mathrm{s}\right)$ $Q_{e}=$ vazão no compartimento 2 (L/s ou $\left.\mathrm{m}^{3} / \mathrm{s}\right)$ No modelo, a fórmula acima leva em conta também as vazões, DBOs e ODs incrementais.

\section{Declividade do rio}

Para os cálculos da declividade do rio Piracicaba, utilizou-se a Equação 2:

$$
D=\frac{D a}{D h}
$$

Onde $\mathrm{D}=$ Declividade, $\mathrm{Da}=$ diferença de altitude, e $\mathrm{Dh}=$ distância do rio. 


\section{Vazão do Rio Piracicaba}

Para o planejamento e gerenciamento de uma bacia hidrográfica, a fim de determinar a capacidade mínima de diluição de um curso de água, consideraram-se as condições críticas que ocorrem exatamente no período de vazão mínima (FERRAZ et al., 1998). Tal vazão deve ser estimada a partir de dados fluviométricos históricos do curso de água, adotando-se usualmente a mínima para um tempo de recorrência de dez anos e mínima de sete dias $\left(Q_{7,10}\right)$. Com isto, estimou-se a $Q_{7,10} \mathrm{com}$ a utilização de uma ferramenta de gestão hidrológica para o Estado de Minas Gerais (HIDROTEC, 2014). Essa ferramenta permite estimar dados hidrológicos para as bacias hidrográficas situadas em Minas Gerais.

Segundo HIDROTEC (2014), na Consulta Espacial Georreferenciada - Modelos ajustados por curso d'água - Bacia do rio Doce, o modelo ajustado da vazão crítica em função da área da bacia para o rio Piracicaba é calculada segundo a Equação 3:

$$
Q_{7,10}=0,0038 A^{1,0129}
$$

Onde $\mathrm{A}=$ área da bacia $\left(\mathrm{km}^{2}\right)$. Sendo a área da bacia do rio Piracicaba igual a $5.685,86 \mathrm{~km}^{2}$, temos que' $Q_{7,10}=24,155 \mathrm{~m}^{3} / \mathrm{s}$ e a vazão especifica $=4,15$ $\mathrm{L} / \mathrm{s} . \mathrm{km}^{2}$. O intervalo válido para a Equação 3 é 272 a $24.204 \mathrm{~km}^{2}$.

$O$ valor da $Q_{7,10}$ foi inserido no modelo para comparação entre a estimativa das vazões calculadas na modelagem e da vazão segundo HIDROTEC (2014). Já a vazão específica foi utilizada para os cálculos das vazões incrementais.

Pela consulta espacial disponível no HIDROTEC (2014), é possível obter a vazão de cabeceira para o rio Piracicaba, que é de $0,301 \mathrm{~m}^{3} / \mathrm{s}$. Esse valor foi inserido como dado de entrada inicial do modelo, onde posteriormente foram realizados os cálculos de vazão ao longo da trajetória do rio Piracicaba.

Visando a obtenção das vazões, como os demais parâmetros hidráulicos (velocidade média e profundidade), foram selecionadas séries históricas das estações fluviométricas localizadas ao longo do rio.

\section{Coeficientes de ajuste}

Considerando que as condições morfométricas dos rios mudam ao longo de seu percurso, portanto é bastante vantajosa em termos de modelagem de qualidade que se obtenha esta equação de ajuste para cada trecho do rio (VON SPERLING, 2014). Desta forma, utilizou-se a fórmula de Manning por meio de equações de ajustes para os diversos trechos em que o rio foi dividido. Para a solução da equação de Manning necessita-se conhecer a declividade " $\mathrm{i}$ " para cada trecho e o coeficiente de rugosidade " $\mathrm{n}$ " de Manning.

Também pode-se obter os dados das vazões, bem como os demais parâmetros hidráulicos (velocidade média e profundidade), por meio das séries históricas de quatro estações fluviométricas pertencentes à rede de monitoramento da Agência Nacional de Águas (ANA) localizadas ao longo do rio, Rio Piracicaba (56610000), Nova Era IV (56659998), Mário de Carvalho (56696000), Nova Era (56659999).

Os dados da série histórica das estações foram lançados em dois sistemas gráficos bidimensionais, $(u, Q)$ e $(y, Q)$, sendo, posteriormente, realizados ajustes não-lineares. Os coeficientes de ajuste, que são calculados em função da velocidade, profundidade e vazão média, foram calculados por meio de regressão de acordo com as equações 4 e 5 : 


$$
\begin{aligned}
& u=a \cdot Q^{b} \\
& y=c \cdot Q^{d}
\end{aligned}
$$

Onde $Q$ = vazão volumétrica ou fluxo do trecho; $u$ = velocidade; $y=$ profundidade do canal e $a, b, c$ e $d$ são constantes empíricas.

A partir dos valores de vazão, foram calculados os valores dos coeficientes de velocidade e profundidade utilizando a média, conforme apresentado na Tabela 1.

Tabela 1: Valores médios dos coeficientes de descarga a, b, c e d.

\begin{tabular}{llll}
\hline Velocidade & Profundidade & \\
\hline A & b & c & d \\
\hline 0,112 & 0,487 & 0,194 & 0,478 \\
\hline
\end{tabular}

\section{Entrada de dados para calibração do modelo}

Os dados de qualidade de água utilizados nesse estudo foram provenientes das campanhas de monitoramento de qualidade de água do "Projeto Águas de Minas", de responsabilidade do Instituto Mineiro de Gestão das Águas (IGAM), e dos arquivos sobre Indicadores de Qualidade da Água da plataforma Metadados, de responsabilidade da Agência Nacional das Águas (ANA). Na bacia do rio Piracicaba, se localizam 12 estações de monitoramento, das quais foram obtidos os dados de qualidade da água para a modelagem, tendo a uma densidade de estações 1,40 por $1000 \mathrm{~km}^{2}$.

Após a inserção dos dados necessários no modelo, foi realizada a calibração utilizando a ferramenta estatística Solver do Microsoft Exce ${ }^{\circledast}$ para estimar os valores de $\mathrm{K}_{1}, \mathrm{~K}_{\mathrm{d}}$ e $\mathrm{K}_{\mathrm{s}}$. Essa ferramenta minimiza os erros quadráticos dos valores experimentais com os valores estimados, gerando como resultado os valores otimizados dos coeficientes $K_{1}, K_{d}$ e $K_{s}$, usada nas equações para modelagem da qualidade da água. Esse método de otimização faz com que a curva estimada se aproxime ao máximo dos valores observados em campo para cada trecho, minimizando o erro entre valor observado e o estimado.

A avaliação do ajuste do modelo foi realizada empregando-se o indicador estatístico RMEQ (Raiz da média dos erros ao quadrado), conforme Equação 6:

$$
R M E Q=\sqrt{\frac{\sum\left(Y_{o b s}-Y_{e s t}\right)^{2}}{n}}
$$

Onde: $\mathrm{Y}_{\mathrm{obs}}=$ valor observado; $\mathrm{Y}_{\mathrm{est}}=$ valor estimado; $\mathrm{n}=$ número de dados.

Segundo Von Sperling (2014), RMEQ tem bom comportamento estatístico e proporciona uma medição direta do erro do modelo. Quanto mais próximo de 0 (zero), melhor o ajuste requerido. Foram realizadas as simulações das instalações de sistemas de tratamento de esgotos domésticos de 4 sedes que efetuam seu lançamento diretamente no rio Piracicaba.

A simulação de cenários de tratamento de esgoto está fundamentada na necessidade de um tratamento eficiente dos efluentes dos municípios que lançam seus efluentes no rio Piracicaba, tendo em vista os valores modelados e o permitido para o rio considerado Classe 2.

A fim de vislumbrar um possível cenário futuro, foram contabilizadas as ETEs fora de operação, em obras e em projeto destacadas no Plano para Incremento do Percentual do Tratamento de Esgotos Sanitário 
da bacia do Rio Piracicaba - PITE Piracicaba (FEAM, 2012). Dessa forma, calculou-se a carga de DBO que seria removida caso essas ETEs estivessem funcionando. Portanto, a situação apresentada no cenário futuro é hipotética, dada a incerteza da concretização dos projetos e finalização das obras. Na Tabela 2 são mostrados os valores de concentrações de DBO gerada e lançada pela população urbana total da bacia do Piracicaba, considerando também o cenário futuro, ou seja, a inclusão das ETEs.

Tabela 2: Estimativa da concentração de DBO lançada no rio Piracicaba.

\begin{tabular}{|c|c|c|c|}
\hline Município & $\begin{array}{l}\text { Concentração lançada } \\
\text { (mgDBO/L) }\end{array}$ & $\begin{array}{lll}\text { Concentração } & \text { removida } & \text { simulando } \\
\text { instalação de ETEs (\%) } & \end{array}$ & $\begin{array}{l}\text { Concentração lançada no cenário } \\
\text { (mgDBO/L) }\end{array}$ \\
\hline Antônio Dias & 557,7 & 6,6 & 520,9 \\
\hline Alvinópolis & 556,1 & 70 & 166,83 \\
\hline Nova Era & 470,7 & 8 & 433,0 \\
\hline $\begin{array}{l}\text { Rio } \\
\text { Piracicaba }\end{array}$ & 608,3 & 83,1 & 102,8 \\
\hline
\end{tabular}

Fonte: FEAM (2012).

No que concerne à quantificação dos impactos qualitativos do lançamento de efluentes, Silva et al. (2004) desenvolveram estudos apoiados em conceitos propostos por Kelman (1997) onde as interferências qualitativas no corpo hídrico são "transformadas" em equivalentes quantitativos. Esse procedimento facilita, significativamente, as análises de outorga que realizam lançamento de efluentes, unificando, dessa forma, as análises quantitativas e qualitativas pertinentes (CAMPOS et al., 2002). A Equação 7 em que se baseia o balanço qualitativo é chamada de Equação de Diluição, proposta por Kelman (1997):

$$
\text { Qdil }=(\text { Qef } X(\text { Cef }- \text { Cperm }) \div(\text { Cperm }- \text { Cnat })
$$

em que:

Qdil = vazão de diluição para determinado parâmetro de qualidade; Qef = vazão do efluente que contém o parâmetro de qualidade analisado;

Cef = concentração do parâmetro de qualidade no efluente;

Cperm = concentração permitida para o parâmetro de qualidade onde é realizado o lançamento; Cnat = concentração natural do parâmetro de qualidade no manancial onde é realizado o lançamento.

A vazão de diluição (Qdil) é a vazão necessária para diluir determinada concentração (Cef) de dado parâmetro de qualidade, de modo que a concentração resultante (Cmistura) seja igual ou menor à concentração permitida (Cperm).

No caso de lançamento de efluentes que possuam poluentes não-conservativos, como a DBO, por exemplo, a concentração resultante na vazão de mistura sofrerá um decaimento natural ao longo do tempo e dos trechos do manancial, decorrente da possibilidade de autodepuração do corpo hídrico. Porém, a vazão da mistura que este usuário torna indisponível no manancial para outras diluições do mesmo parâmetro é aqui chamada de Vazão Indisponível (Qindisp). A vazão indisponível no ponto de lançamento pode ser determinada pela Equação 8.

$$
\text { Qind }=Q d i l+Q e f
$$

O balanço qualitativo deve ser realizado quantificando-se em todos os trechos, a vazão indisponível total de cada parâmetro de qualidade, com ou sem decaimento, proveniente dos diversos lançamentos efetuados. Para determinar a variação das vazões de diluição após cada lançamento considerando a capacidade de autodepuração foi inserida nas planilhas em Excel ${ }^{\circledR}$ a Equação 9 proposta por (SILVA et al., 
2004):

$$
\text { Qind }=\left((Q e f+\text { Qdil }) X \text { Cperm } 1 X e^{-k_{1} \cdot t}\right) \div \text { Cpermn }
$$

Qind = vazão indisponível no ponto de lançamento $\left(\mathrm{em} \mathrm{m}^{3} / \mathrm{s}\right)$; Qef = vazão do efluente $\left(\mathrm{em} \mathrm{m}^{3} / \mathrm{s}\right)$; $\mathrm{K}_{1}$ = coeficiente de desoxigenação $\left(\right.$ dia $\left.^{-1}\right)$; $\mathrm{t}=$ tempo de percurso (em dias) do trecho onde ocorre o lançamento até o trecho onde se deseja calcular a vazão indisponível;

Cperm1 = concentração permitida de $\mathrm{DBO}_{5}$ para o manancial no trecho onde ocorre o lançamento; Cpermn $=$ concentração permitida de $\mathrm{DBO}_{5}$ no trecho do manancial onde será calculada a vazão indisponível. $Q d i l=$ vazão de diluição no trecho onde ocorre o lançamento $\left(\mathrm{em} \mathrm{m}^{3} / \mathrm{s}\right)$.

\section{RESULTADOS E DISCUSSÃO}

Após a inserção dos dados de entrada, foi obtida a vazão ao longo do rio Piracicaba, Figura 2, mostrando que a estimativa de vazão pelo modelo é próxima do valor de $Q_{7,10}$ para HIDROTEC (2014).

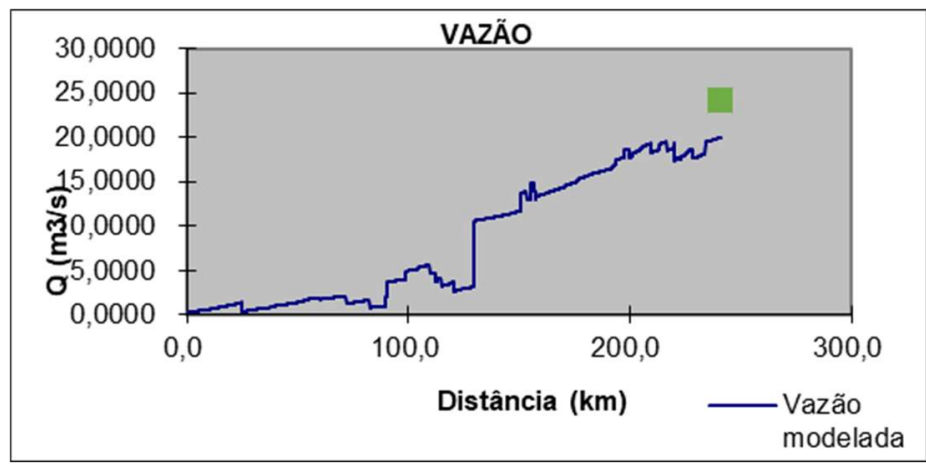

Figura 2: Vazão x Distância do rio Piracicaba obtido no modelo QUAL-UFMG.

O ponto representado pela vazão obtida de HIDROTEC (2014) não coincide com o ponto final modelado pois a modelagem leva em consideração as captações do rio Piracicaba. Já a $Q_{7,10}$ segundo HIDROTEC (2014), é calculada pela área da bacia, sem levar em consideração os volumes retirados do rio.

A Figura 2 mostra que a calibração da vazão ocorreu de forma adequada. Em um estudo sobre autodepuração no rio Piracicaba, Mourão Junior (2010) encontra uma curva semelhante na modelagem de vazão. Da análise da Figura 2 pode-se constatar que ao longo do percurso do Rio Piracicaba, a vazão passa por aumentos abruptos devido, principalmente, aos afluentes. Todavia, há também declinações ao longo do percurso. 0 primeiro trecho em que isso é observado é próximo ao $\mathrm{km} 25$ devido às captações existentes neste trecho. Após isso, a curva apresenta acréscimos e decréscimos devido aos tributários que desaguam no rio Piracicaba e às captações efetuadas, respectivamente.

Por volta do km 90 há dois tributários com maior vazão que desaguam no rio estudado, o ribeirão Turvo e o rio Maquiné. Do km 110 ao 120 há captações que são evidenciadas pelo declínio da curva de vazão. No km 130 há uma grande contribuição devido à vazão do tributário rio Santa Bárbara, que pode ser percebido pelo acréscimo abrupto na curva. Por volta do km 50 há dois picos de vazões, representados pelo rio da Prata e rio do Peixe, respectivamente. Após isso, há um aumento da vazão devido ao desaguamento de alguns tributários no rio Piracicaba. Em determinados pontos há também a declinação da curva devido às captações. Logo, a vazão dos tributários e as captações exercem variações significantes no perfil de descarga. 


\section{OD e DBO}

Para início da modelagem de OD e DBO, foram inseridos os dados médios da série histórica das estações de qualidade da água de monitoramento do IGAM e da plataforma Metadados - ANA. É importante ressaltar que parte dos dados de DBO das estações ficaram abaixo do limite de quantificação do método utilizado, sendo assim, não foi possível obter um valor exato desse parâmetro. Esses valores abaixo do limite de quantificação não mostram a realidade do corpo hídrico, o que prejudicou que a calibração ocorresse de forma adequada. Nas estações onde os valores constam como " $<2$ ", admitiu-se 2, para possibilitar a calibração.

$\mathrm{Na}$ tentativa de melhorar o ajuste, testou-se as diversas formas para obtenção de $\mathrm{K}_{2}$, e a que melhor se adequou à curva foi a equação proposta por O'Connor et al. (1958) apresentada na Tabela 3. Outro fator que afeta diretamente na calibração é a utilização dos valores adequados de velocidade e profundidade do rio. Para isso, inseriu-se os valores dos coeficientes por meio dos cálculos realizados presentes na Tabela 6.

Para uma calibração mais acurada foi utilizada a ferramenta Solver do Excel ${ }^{\circledR}$. Após essa etapa, obteve-se os dados dos coeficientes $\mathrm{K}_{1}, \mathrm{~K}_{\mathrm{d}}$ e $\mathrm{K}_{\mathrm{s}}$, orientados pelos limites do quadro 1 . Com isso, foram obtidos os valores de $K_{1}, K_{d}$ e $K_{s}$ da Tabela 3.

Tabela 3: Valores de $K_{1}, K_{d}$ e $K_{s}$ após calibração utilizando solver.

\begin{tabular}{llll}
\hline Distância $(\mathrm{km})$ & $\mathrm{K}_{1}$ & $\mathrm{~K}_{\mathrm{d}}$ & $\mathrm{K}_{\mathrm{s}}$ \\
\hline 0,0 até 25,3 & 0,07 & 0,09 & 0 \\
25,4 até 27,7 & 0,07 & 0,17 & 0 \\
27,8 até 29,7 & 0,07 & 0,06 & 0 \\
29,8 até 45,6 & 0,07 & 0,09 & 0 \\
45,7 até 48,2 & 0,07 & 0 & 0 \\
48,3 até 63,9 & 0,07 & 0,08 & 0,09 \\
64,0 até 97,1 & 0,07 & 0,09 & 0,19 \\
97,2 até 98,9 & 0,35 & 0 & 0,19 \\
99,0 até 111,6 & 0,35 & 0,39 & 0,19 \\
111,7 até 115,2 & 0,17 & 0,19 \\
115,3 até 119,7 & 0,17 & 0,87 & 0,19 \\
119,7 até 121,8 & 0,39 & 0 & 0,19 \\
121,9 até 136,5 & 0,07 & 0,87 & 0 \\
136,6 até 139,2 & 0,07 & 0,87 & 0,05 \\
139,3 até 141,8 & 0,39 & 0,17 & 0,05 \\
141,9 até 142,7 & 0,39 & 0,44 & 0 \\
142,8 até 178,4 & 0,07 & 0 & 0 \\
178,5 até 184,1 & 0,09 & 0,08 & 0 \\
184,2 até 216,1 & 0,07 & 0,17 & 0,05 \\
216,2 até 241 & 0,09 & 0,08 & 0,13 \\
\hline
\end{tabular}

A raiz da média dos erros ao quadrado (RMEQ) foi utilizada para avaliar o erro produzido pelo modelo. Quanto mais próximo de zero, melhor o comportamento estatístico da modelagem (JAWORSKA et al., 2001; BROWN et al., 1987). O índice RMEQ da modelagem de OD foi de 0,005. Para a modelagem de DBO foram calculados 2 índices, um utilizando os valores <LQ das estações como comparação, e outro desconsiderando estes valores. Para o primeiro caso o índice foi de 0,7 e para o segundo caso o índice calculado foi de 0,1. Percebe-se que a utilização de valores imprecisos afeta na calibração da modelagem. Esses métodos de otimização fazem com que a curva estimada se aproxime ao máximo dos valores 
observados em campo para cada trecho, minimizando o erro entre valor observado e estimado, sendo mostrado nas Figuras 3 e 4 as modelagens de OD e DBO, respectivamente.

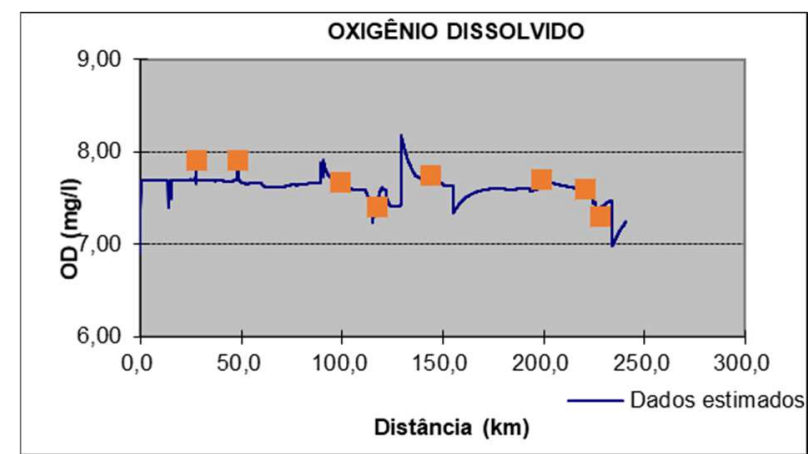

Figura 3: OD x Distância, obtido no modelo QUALUFMG.

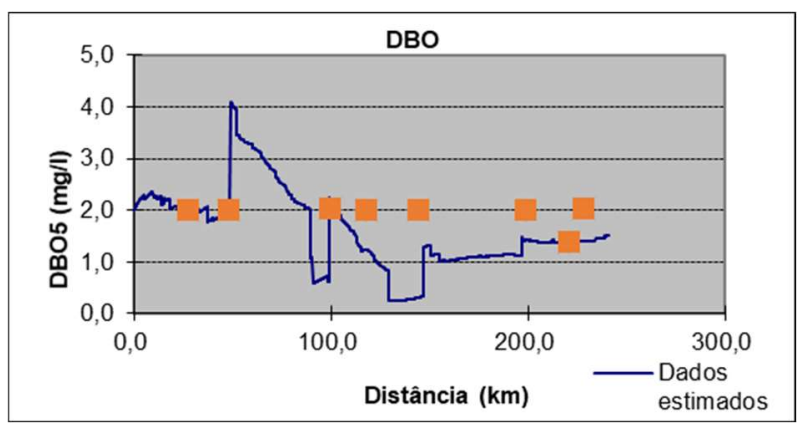

Figura 4: DBO x Distância, obtido no modelo QUALUFMG.

As Figuras 3 e 4, mostram uma boa concordância entre os valores estimados e observados tanto para os dados de entrada iniciais, como também aos valores calibrados de $\mathrm{K}_{1}$, $\mathrm{K}_{\mathrm{d}}$ e $\mathrm{K}_{\mathrm{s}}$ pelo Solver. Mourão Junior (2010) em um estudo de modelagem no rio Piracicaba observou que o ajuste da curva de decaimento da DBO com os dados de campo, considerando que o limite de detecção da DBO é <2,0, pode ser considerado como razoável. Apesar de não conseguir representar grandes variações pontuais, a simulação conseguiu acompanhar a curva de tendência.

Da análise da Figura 4, constata-se que nos $20 \mathrm{Km}$ iniciais, ocorre uma queda na concentração de OD devido ao lançamento de efluentes industriais. Aos 30 e $50 \mathrm{Km}$, ocorre um aumento na concentração de OD devido á confluência com tributários, dentre eles o córrego Faria e o ribeirão Durão. No trecho posterior, há aumento do $O D$, pois uma parcela da matéria orgânica já se encontra estabilizada.

Concomitantemente, ocorre a introdução de oxigênio atmosférico na massa líquida, aumentando os teores de OD (a reaeração e incorporação de oxigênio passa a ser maior que o consumo de oxigênio para a estabilização da matéria orgânica). Este mesmo processo ocorre no decorrer da modelagem. Nas proximidades do km 90 há uma ascendência na concentração de OD devido ao desaguamento do ribeirão Turvo e do rio Maquiné. Entre os km 110 e 115 há uma decaída na concentração de OD devido ao ponto de confluência com o córrego Jacuí (tributário impactado pelos efluentes de João Monlevade), assim como também pelas captações existentes neste trecho, fazendo com que a vazão disponível para diluição e degradação da matéria orgânica seja menor, consequentemente aumentando a concentração de DBO, e causando a diminuição de OD.

Neste trecho foi observada a menor concentração de OD resultante da modelagem $(6,98 \mathrm{mg} / \mathrm{L})$, e isso ocorre devido à proliferação bacteriana, com predominância das aeróbias, consumindo o OD disponível no meio para os seus processos metabólicos. Entretanto, em alguns pontos há ascendência devido à contribuição dos afluentes no rio Piracicaba.

Analisando-se a Figura 05 foi possível perceber que no começo da modelagem há elevações nas concentrações de DBO devido ao lançamento de efluentes industriais e às captações. Há também diminuições na concentração de DBO devido às contribuições incrementais pelos afluentes. 
Próximo ao km 35 há diminuição de DBO devido à contribuição do córrego Faria. Por volta do km 50 há um aumento considerável da concentração de DBO devido ao lançamento de efluentes de Fonseca. É importante destacar que neste trecho a vazão do rio Piracicaba é considerada baixa se comparado aos trechos próximos à foz, por isso o lançamento de Fonseca se mostra expressivo na curva de DBO. Após isso, há uma diminuição significativa de DBO devido à autodepuração do rio, assim como o desaguamento de tributários que auxiliam na diluição de efluentes.

Ao longo do km 90 há uma queda considerável devido ao recebimento do Ribeirão Turvo e posteriormente do rio Maquiné, que contribuem consideravelmente com a vazão. Por volta do km 100 há um aumento de DBO devido ao lançamento de efluentes do município de Rio Piracicaba. Após isso, há atenuação da curva devido ao processo de autodepuração, e aos pontos de confluência com tributários.

Ao longo do km 150, ocorre um aumento na concentração de DBO devido o lançamento de efluentes domésticos de Nova Era. Em seguida há uma queda de DBO devido principalmente ao desaguamento do rio da Prata e rio do Peixe. Após isso há um leve crescimento na curva devido às captações existentes, assim como alguns lançamentos industriais. Próximo ao km 200 há o recebimento de efluentes de Antônio Dias, por isso a concentração de DBO aumenta. Por fim, há uma leve atenuação da curva devido aos afluentes, seguido de um pequeno aumento devido aos efluentes domésticos e industriais próximo à foz do rio Piracicaba. O rio Piracicaba pertence à classe 2 de enquadramento e, segundo os cálculos da modelagem, todo o trecho estudado atende aos valores máximos permitidos dos parâmetros OD e DBO.

\section{Simulação de cenário de tratamento de efluentes}

Foi efetuada uma simulação a partir da remoção da carga orgânica em virtude de uma hipotética instalação de sistemas de tratamento de esgotos domésticos em Antônio Dias, Fonseca, Rio Piracicaba e Nova Era. Os valores de concentração de DBO gerada e lançada pela população, considerando o cenário futuro, ou seja, a inclusão das ETEs fora de operação e com chance de reativação, as ETEs em obras e as ETEs em projeto. Com isso, mantendo os parâmetros cinéticos previamente determinados na calibração, foi simulado um cenário hipotético para a bacia, avaliando as variáveis OD e DBO, Figura 5 e 6.

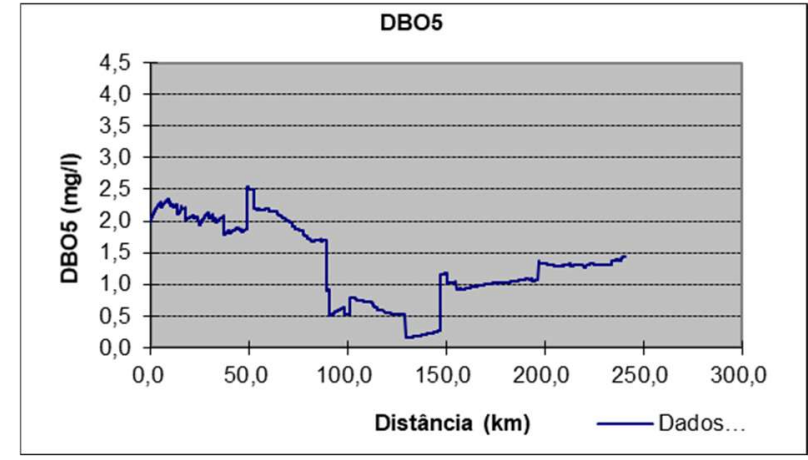

Figura 5: OD x Distância do rio Piracicaba no cenário de tratamento de efluentes.

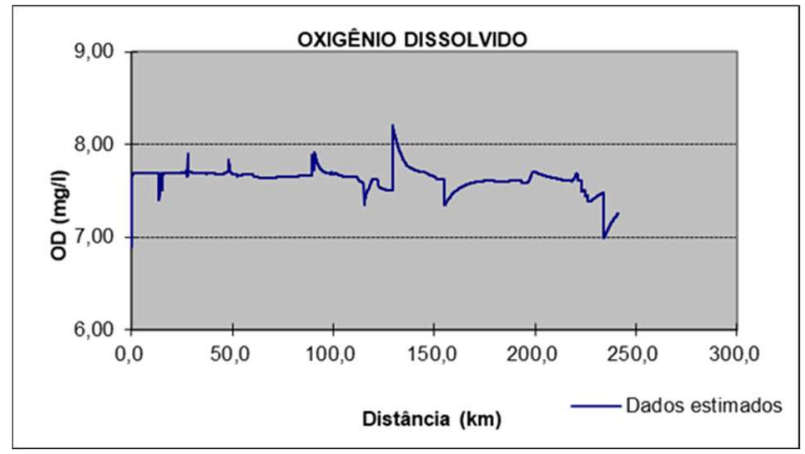

Figura 6: DBO x Distância do rio Piracicaba no cenário de tratamento de efluentes.

Da Figura 5, constata-se que houve poucas alterações nos valores de OD devido à instalação hipotética das ETEs. Da Figura 6 verificou-se que, em virtude do funcionamento das ETEs, as concentrações 
de DBO diminuíram nos pontos onde ocorriam os lançamentos de efluentes.

Nas proximidades do km 50 e 100 há uma diminuição de 48,44\% da concentração de DBO se comparado à Figura 5, devido ao tratamento dos efluentes domésticos de Fonseca e Rio Piracicaba. 0 tratamento de efluentes de Nova Era e de Antônio Dias não impactaram de forma expressiva (apenas 10,72\%) no decréscimo da curva de DBO devido à baixa porcentagem de carga removida prevista na instalação de ETEs segundo o (FEAM, 2012). Nos trechos em que ocorreriam os lançamentos de efluentes houve um decréscimo considerável na concentração de DBO se comparado à modelagem do trecho sem considerar a simulação. Os resultados demonstraram a necessidade do aumento da eficiência do tratamento de efluentes.

\section{Vazão de diluição}

Após a inserção das equações, obteve-se um gráfico considerando todos lançamentos de efluentes no rio Piracicaba e a concentração permitida considerando sua respectiva classe de enquadramento atual (Classe 2), Figura 7. Na Tabela 4 são mostrados os valores das vazões de diluição, vazões indisponíveis e vazões disponíveis de acordo com os cálculos realizados.

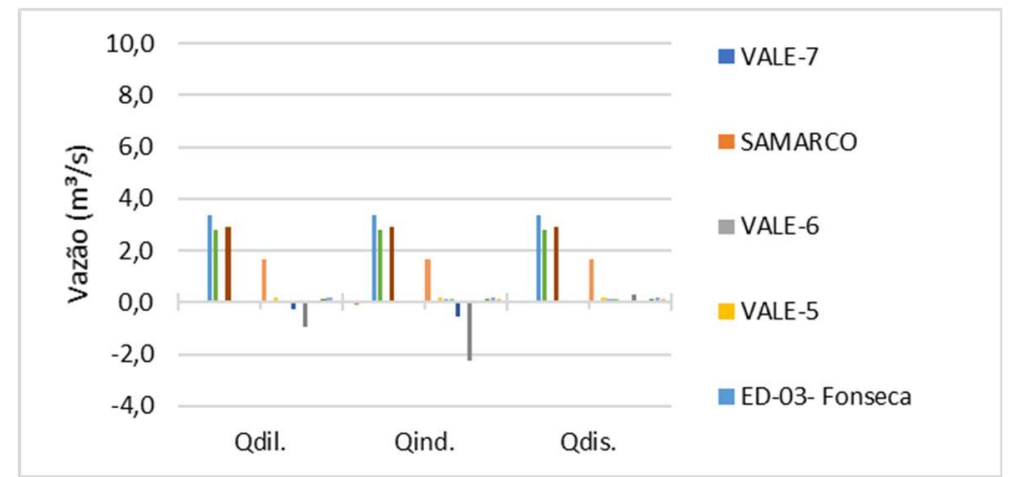

Figura 7: Vazões de diluição, indisponível e disponível na classe atual do rio (Classe 2).

Tabela 4: Vazões de diluição, indisponível e disponível para a classe atual do rio (Classe 2).

\begin{tabular}{llll}
\hline Empreendimento & Qdil. $\left(\mathrm{m}^{3} / \mathrm{s}\right)$ & Qind. $\left(\mathrm{m}^{3} / \mathrm{s}\right)$ & Qdis. $\left(\mathrm{m}^{3} / \mathrm{s}\right)$ \\
\hline Vale-7 & 0,0004 & 0,0008 & 0,0008 \\
Samarco & $-0,0629$ & $-0,1015$ & 0,0243 \\
Vale-6 & 0,0040 & 0,0044 & 0,0238 \\
Vale-5 & 0,0294 & 0,0827 & 3,3658 \\
ED-03-Lançamento de Fonseca & 3,3613 & 3,3668 & 2,8034 \\
ED-37 e 38 - Rio Piracicaba & 2,7949 & 2,8080 & 0,0018 \\
ARCELOR (somar tudo) & 0,0004 & 0,0026 & 2,9264 \\
ED-35 - Nova Era & 2,9037 & $-0,0001$ \\
Vale-1 & $-0,0001$ & $-0,0001$ \\
Vale-4 & $-0,0001$ & $-0,0001$ \\
Vale-2 & $-0,0001$ & $-0,0001$ \\
Vale-3 & $-0,0001$ & 0,0001 \\
Consórcio UHE & 0,0001 & $-0,0001$ & 1,6803 \\
ED-07 - Antônio Dias & 1,6699 & $-0,0001$ & 0,0013 \\
Paladar & 0,0001 & $-0,0001$ & 0,1615 \\
ED-24 - Jaguaraçu & 0,1605 & 0,0001 & 0,1041 \\
Harsco & 1,6806 & 0,1496 \\
Arcelor Inox-1 & 0,0962 & 0,0013 & $-0,0056$ \\
Arcelor Inox -2 & 0,0040 & 0,1615 & 0,0354 \\
ED-21 - Coronel Fabriciano & $-0,2862$ & 0,1041 & 0,3203 \\
Usiminas (Tudo) & 0,0352 & $-0,0037$ \\
Unigal (Tudo) & $-0,9732$ & $-0,1497$ & $-0,034$ \\
White Martins & $-0,0183$ & 0,1092 \\
ETE Horto & $-0,0123$ & $-2,2669$ &
\end{tabular}


ETE Areal

ETE Bela Vista
0,1894 0,0969
0,2001 0,1063
0,2001 0,1063

Para os cálculos das vazões de diluição da Equação 7, adotou-se como concentração natural do parâmetro DBO de qualidade no manancial onde é realizado o lançamento a concentração atual do parâmetro no determinado ponto de lançamento. Isso pode ser justificado pois a concentração atual de DBO quase sempre é maior que a concentração natural do rio, sendo possível estimar o quanto cada usuário comprometerá qualitativamente o manancial de forma dependente e considerando as interferências de outros usuários (LISBOA, 2014; DROLC et al., 2000).

Adotando-se a concentração atual de DBO do manancial, percebeu-se que algumas vazões de diluição apresentaram o resultado negativo, significando falta de água para a diluição dos efluentes lançados. Essa condição faz com que todas as análises retratem situações que são influenciadas pelos usos existentes, mascarando o real efeito que cada usuário causa ao manancial separadamente, analisando os efeitos no rio como um todo. Para comparação das vazões de diluição, vazões indisponíveis e vazões disponíveis no cenário de instalação de ETEs, realizou-se os mesmos cálculos das Equações 7, 8 e 9, Figura 8. A Tabela 5 retrata os valores das vazões de diluição, vazões indisponíveis e vazões disponíveis para o de tratamento de efluentes de Antônio Dias, Fonseca, Nova Era e Rio Piracicaba.

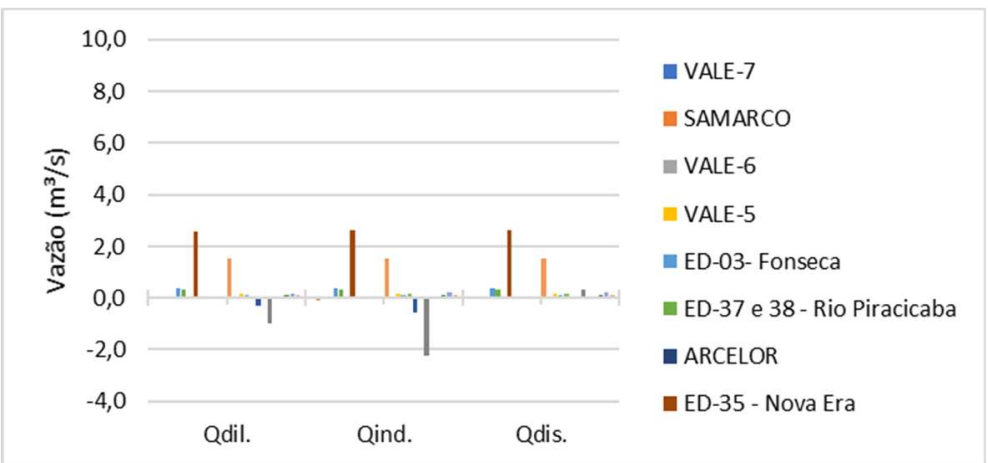

Figura 8: Vazões de diluição, indisponível e disponível no cenário de tratamento de efluentes.

Tabela 5: Vazões de diluição, indisponível e disponível no cenário de tratamento de efluentes.

\begin{tabular}{llll}
\hline Empreendimento & Qdil. $\left(\mathrm{m}^{3} / \mathrm{s}\right)$ & Qind.( $\left.\mathrm{m}^{3} / \mathrm{s}\right)$ & Qdis. $\left(\mathrm{m}^{3} / \mathrm{s}\right)$ \\
\hline Vale-7 & 0,0004 & 0,0008 \\
Samarco & $-0,0629$ & 0,0008 & $-0,0243$ \\
Vale-6 & 0,0040 & $-0,1015$ & 0,0044 \\
Vale-5 & 0,0294 & 0,0044 & 0,0238 \\
ED-03-Lançamento de Fonseca & 0,3608 & 0,0827 & 0,3662 \\
ED-37 e 38 - Rio Piracicaba & 0,3054 & 0,3663 & 0,3180 \\
Arcelor (somar tudo) & 0,0003 & 0,3185 & 0,0018 \\
ED-35 - Nova Era & 2,5870 & 0,0025 & 2,6097 \\
Vale-1 & $-0,0001$ & 2,6103 & $-0,0001$ \\
Vale-4 & $-0,0001$ & $-0,0001$ \\
Vale-2 & $-0,0001$ & $-0,0001$ & $-0,0001$ \\
Vale-3 & $-0,0001$ & $-0,0001$ \\
Consórcio UHE & 0,0001 & 0,0001 \\
ED-07 - Antônio Dias & 1,5260 & $-0,0001$ & 1,5364 \\
Paladar & 0,0001 & 0,0001 & 0,0013 \\
ED-24 - Jaguaraçu & 0,1578 & 0,0001 & 0,1588 \\
Harsco & 0,0948 & 1,5367 & 0,1026 \\
Arcelor Inox-1 & 0,0039 & 0,1496 \\
ARCELOR INOX -2 & $-0,2822$ & 0,1588 & $-0,0015$ \\
ED-21 - Coronel Fabriciano & 0,0347 & 0,0349 \\
Usiminas (Tudo) & $-0,9616$ & 0,1027 & 0,3320
\end{tabular}




\begin{tabular}{|c|c|c|c|}
\hline Unigal (Tudo) & $-0,0180$ & $-0,0326$ & $-0,0034$ \\
\hline White Martins & $-0,0122$ & $-0,0210$ & $-0,0033$ \\
\hline ETE Horto & 0,1038 & 0,1079 & 0,1079 \\
\hline ETE Areal & 0,1872 & 0,1979 & 0,1979 \\
\hline ETE Bela Vista & 0,0957 & 0,1051 & 0,1051 \\
\hline
\end{tabular}

Constatou-se que as vazões de diluição, indisponíveis e disponíveis necessárias para atendimento do parâmetro DBO de acordo com a classe 2 de enquadramento diminuiu em 59,21\%, 49,68\% e 50,34\%, respectivamente, com a instalação dos sistemas de tratamentos de efluentes de acordo com a Tabela 19. Conforme citado anteriormente, essa diminuição se mostrou mais expressiva com o tratamento de efluentes domésticos de Fonseca e de Rio Piracicaba, pois estes sistemas preveem uma porcentagem maior de carga removida do que o previsto para Antônio Dias e Nova Era. Para os dois municípios, os valores de vazões necessárias para diluição diminuem de forma imperceptível pelo gráfico de barras, mostrando a necessidade de aumentar a porcentagem de remoção de carga orgânica nas ETEs de Antônio Dias e Nova Era. Outra forma de comparar as vazões de diluição, vazões indisponíveis e vazões disponíveis foi feita admitindo-se hipoteticamente que o rio Piracicaba pertence à Classe 1 de enquadramento, Figura 9. A Tabela 6 mostra os valores das vazões de diluição, vazões indisponíveis e vazões disponíveis admitindo-se que o rio Piracicaba pertence à Classe 1 de enquadramento.

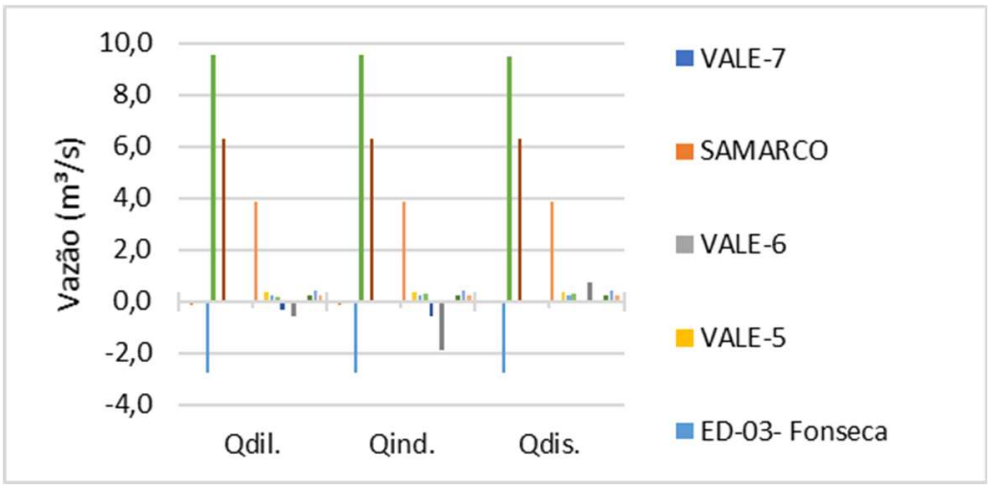

Figura 9: Vazões de diluição, indisponível e disponível considerando o rio como Classe 1.

Tabela 6: Vazões de diluição, indisponível e disponível considerando o rio como Classe 1.

\begin{tabular}{llll}
\hline Empreendimento & Qdil. $\left(\mathrm{m}^{3} / \mathrm{s}\right)$ & Qind. $\left(\mathrm{m}^{3} / \mathrm{s}\right)$ & Qdis. $\left(\mathrm{m}^{3} / \mathrm{s}\right)$ \\
\hline Vale-7 & 0,0026 & 0,0030 & $-0,0839$ \\
Samarco & $-0,1225$ & $-0,1610$ & 0,0147 \\
Vale-6 & 0,0144 & 0,0857 \\
Vale-5 & 0,0324 & 0,0147 & $-2,7571$ \\
ED-03-Lançamento de Fonseca & $-2,7634$ & 0,0857 & 9,5253 \\
ED-37 e 38 - Rio Piracicaba & 9,5278 & $-2,7689$ & 0,0037 \\
Arcelor (somar tudo) & 0,0015 & 9,5409 & 6,3053 \\
ED-35 - Nova Era & 6,2834 & 0,0037 & $-0,0001$ \\
Vale-1 & $-0,0001$ & 6,3067 & $-0,0001$ \\
Vale-4 & $-0,0001$ & $-0,0001$ & $-0,0001$ \\
Vale-2 & $-0,0001$ & $-0,0001$ & $-0,0001$ \\
Vale-3 & $-0,0001$ & $-0,0001$ & 0,0001 \\
Consórcio UHE & 0,0001 & $-0,0001$ & 3,8605 \\
ED-07 - Antônio Dias & 3,8505 & 0,0001 & 0,0029 \\
Paladar & 0,0018 & 3,8612 & 0,3636 \\
ED-24 - Jaguaraçu & 0,3626 & 0,0029 & 0,2296 \\
Harsco & 0,2218 & 0,3636 & 0,3336 \\
Arcelor Inox-1 & 0,1880 & 0,2297 & $-0,0125$ \\
Arcelor Inox -2 & $-0,2932$ & 0,3337 & 0,0792 \\
ED-21 - Coronel Fabriciano & 0,0790 & $-0,5738$ & 0,7236 \\
Usiminas (Tudo) & $-0,5699$ & 0,0792 &
\end{tabular}




\begin{tabular}{llll} 
Unigal (Tudo) & $-0,0229$ & $-0,0375$ & $-0,0083$ \\
White Martins & $-0,0167$ & $-0,0256$ & $-0,0078$ \\
ETE Horto & 0,2442 & 0,2483 & 0,2482 \\
ETE Areal & 0,4497 & 0,4604 & 0,4603 \\
ETE Bela Vista & 0,2368 & 0,2462 & 0,2462 \\
\hline
\end{tabular}

A classe 1 por ser a mais restritiva apresenta os maiores valores de vazão de diluição, e por consequência, a maior indisponibilidade de água para outorga. Percebeu-se um aumento de $76,39 \%, 64,09 \%$ e 64,04\% das vazões de diluição, indisponível e disponível, respectivamente.

O número de lançamentos com valores de vazão disponível negativos foi mais expressivo se comparando aos valores de vazão disponível de classe 2. Nas condições simuladas para classe 1, o corpo d'água em vários pontos não suporta a carga de matéria orgânica lançada, necessitando de uma melhor alocação de cargas na bacia ou aumento na eficiência de tratamento dos efluentes (MBULIGWE et al., 2005). Por fim, comparou-se as vazões de diluição, vazões indisponíveis e vazões disponíveis admitindo-se supostamente que o rio Piracicaba pertence à Classe 3 de enquadramento. Os resultados estão na Figura 10. A Tabela 7 indica os valores das vazões de diluição, vazões indisponíveis e vazões disponíveis admitindo-se que o rio Piracicaba pertence à Classe 3 de enquadramento.

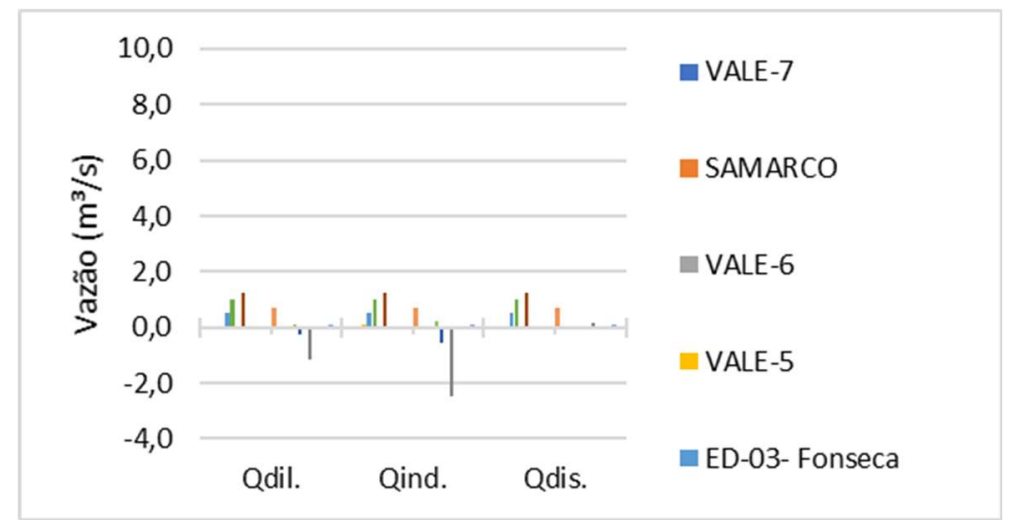

Figura 10: Vazões de diluição, indisponível e disponível considerando o rio como Classe 3.

Tabela 7: Vazões de diluição, indisponível e disponível considerando o rio como Classe 3.

\begin{tabular}{llll}
\hline Empreendimento & Qdil. $\left(\mathrm{m}^{3} / \mathrm{s}\right)$ & Qind. $\left(\mathrm{m}^{3} / \mathrm{s}\right)$ & Qdis. $\left(\mathrm{m}^{3} / \mathrm{s}\right)$ \\
\hline Vale-7 & 0,0001 & 0,0005 & 0,0003 \\
Samarco & $-0,0474$ & $-0,0851$ & 0,0088 \\
Vale-6 & 0,0013 & 0,0086 \\
Vale-5 & 0,0448 & 0,0016 & 0,5138 \\
ED-03-Lançamento de Fonseca & 0,5084 & 0,0981 & 1,0143 \\
ED-37 e 38 - Rio Piracicaba & 1,0028 & 0,5138 & 0,0008 \\
Arcelor (somar tudo) & 0,0015 & 1,0158 & 1,2508 \\
ED-35 - Nova Era & 1,2278 & 0,0036 & $-0,0001$ \\
Vale-1 & $-0,0001$ & $-0,0001$ \\
Vale-4 & $-0,0001$ & $-0,0001$ \\
Vale-2 & $-0,0001$ & $-0,0001$ & -0001 \\
Vale-3 & $-0,0001$ & $-0,0001$ & 0,0001 \\
Consórcio UHE & 0,0001 & $-0,0001$ & 0,6967 \\
ED-07 - Antônio Dias & 0,6861 & $-0,0001$ & 0,0006 \\
Paladar & 0,0005 & 0,0001 & 0,0677 \\
ED-24 - Jaguaraçu & 0,0666 & 0,6968 & 0,0441 \\
Harsco & 0,0360 & 0,0017 & 0,0631 \\
Arcelor Inox-1 & 0,0827 & $-0,0024$ \\
Arcelor Inox -2 & $-0,2830$ & 0,0676 & 0,0149 \\
ED-21 - Coronel Fabriciano & 0,0439 & 0,1338 \\
Usiminas (Tudo) & 0,0146 & $-0,0016$ \\
Unigal (Tudo) & $-1,1598$ & $-0,5636$ &
\end{tabular}




\begin{tabular}{llll} 
White Martins & $-0,0103$ & $-0,0192$ & $-0,0015$ \\
ETE Horto & 0,0414 & 0,0455 & 0,0456 \\
ETE Areal & 0,0722 & 0,0829 & 0,0831 \\
ETE Bela Vista & 0,0345 & 0,0439 & 0,0441 \\
\hline
\end{tabular}

Na CONAMA 357/2005, na classe 3, a simulação para essa condição resultou em pequenas quantidades de água para diluir a carga lançada e elevada quantidade apropriada para diluição. Percebeu-se uma diminuição de $79,83 \%, 66,82 \%$ e $66,92 \%$ das vazões de diluição, indisponível e disponível, respectivamente.

A classe de enquadramento exerce significativa influência nas vazões de diluição, com aumento dos valores consoante ao nível e restrição, ou seja, cada vez que diminui a concentração de DBO permitida no corpo d'água, a vazão de diluição eleva-se.

Em estudo sobre a capacidade de autodepuração do rio Piracicaba, Fraga (2015) mostrou que, apesar dos lançamentos de efluentes domésticos e industriais aumentarem na medida em que se direciona para a foz do rio, não foram observados mais trechos cujos valores de DBO ultrapassaram os limites estabelecidos pela legislação. Isto é justificado pelo aumento da vazão no rio que provoca uma maior diluição dos efluentes.

De acordo com as condições simuladas para esse trabalho, a consideração dos lançamentos anteriores é de extrema importância para a determinação das vazões de diluição e consequente disponibilidade hídrica. Porém, para determinação dos custos pela diluição de efluentes, não se devem considerar os lançamentos anteriores, porque dessa maneira, usuários de jusante estariam pagando por uma indisponibilidade hídrica que não foi devida ao seu lançamento.

\section{CONCLUSÕES}

A metodologia de outorga para lançamento de efluentes no rio Piracicaba deve ser baseada em metodologias que se apoiam em uma análise da capacidade de autodepuração do rio, com o intuito de alocar de maneira otimizada as vazões de diluição respeitando a classe de enquadramento. Se em algum ponto a vazão disponível para outorga for inferior à requerida para diluição de efluentes, sugere-se determinar a redução de carga necessária ou então outra localização ao longo do curso d'água com disponibilidade hídrica.

Com a calibração adotada para o modelo, os valores de OD e DBO foram satisfatórios. Ressaltandose que para os trechos do km 117, km 145, km 198 e km 227 não houve ajuste adequado da curva para a variável DBO devido à $89,4 \%$ dos valores serem menores que $2 \mathrm{mg} / \mathrm{L}$.

A simulação hipotética de instalação de sistemas de tratamento de efluentes domésticos para alguns lançamentos diretamente no rio Piracicaba demonstrou um decréscimo de 36,96\% na concentração de DBO, o que contribuiria para a manutenção da qualidade do rio caso essas ETEs estivessem em funcionamento.

A mudança nas classes de enquadramento resultou em variações de até $79,83 \%$ nas vazões de diluição. Com o aumento da restrição, diminuindo os valores permitidos de DBO no rio, as vazões de diluição tiveram seus valores aumentados de forma acentuada.

AGRADECIMENTOS: O presente trabalho foi realizado com apoio da coordenação de Aperfeiçoamento de 
Pessoal Nível Superior (CAPES) - Código de Financiamento 001, no âmbito do Programa de Mestrado Profissional em Rede Nacional em Gestão e Regulação de Recursos Hídricos - PROFÁGUA, Projeto CAPES/ANA AUXPE №. 2717/2015.

\section{REFERÊNCIAS}

ABBASPOUR, K. C.; ROUHOLAHNEJAD, E.; VAGHEFI, S.; SRINIVASAN, R.; YANG, H.; KLOVE, K.. A Continental-Scale Hydrology and Water Quality Model for Europe: Calibration and Uncertainty of a High-Resolution Large-Scale SWAT Model. Journal of Hydrology v.524, p.733-752, 2015. DOI: https://doi.org/10.1016/j.jhydrol.2015.03.027

AMORIM JUNIOR, J. C.; LIMA, L. C. S.; VIEIRA, P. L. C.. Estudo da autodepuração em trecho do rio Jucu, Vila Velha-ES, utilizando os modelos matemáticos QUAL-UFMG e StreeterPhelps. In: CONGRESSO BRASILEIRO DE ENGENHARIA SANITÁRIA E AMBIENTAL, 26. Anais. Porto Alegre: ABES, 2011.

ANA. Agência Nacional de Águas. Resolução no 219, de 6 de junho de 2005. Diretrizes para análise e emissão de outorga de direito de uso de recursos hídricos para fins de lançamento de efluentes. ANA, 2005.

ANA. Agência Nacional de Águas. Caderno de Recursos Hídricos, Panorama do enquadramento dos corpos d'água do Brasil e Panorama da qualidade das águas subterrâneas no Brasil. ANA, 2007.

BALDOCHI, M. A.. Utilização do modelo QUAL2E como apoio ao gerenciamento da qualidade das águas da bacia do córrego dos Bagres. Dissertação (Mestrado em Engenharia Ambiental) - Universidade de São Paulo, São Carlos, 2002.

BÁRBARA, V. F.. Uso do modelo Qual2e no estudo da qualidade da água e da capacidade de autodepuração do rio Araguari - Ap (Amazônia). Dissertação (Mestrado em Engenharia Ambiental) - Universidade Federal de Goiás, Goiânia, 2006.

BRAGA JUNIOR, B. P. F.; HESPANHOL, I.; LOTUFO CONEJO, J. G.; BARROS, M. T. L.; VERAS JUNIOR, M. S.; PORTO, M. F. A.. Introdução à engenharia ambiental. São Paulo: Prentice Hall. 2002.

BRASIL. Lei Federal no 9.433, de 8 de janeiro de 1997. Institui a Política Nacional de Recursos Hídricos, cria o Sistema Nacional de Gerenciamento de Recursos Hídricos. Brasília: DOU, 1997.

BROWN, L. C.; BARNWELL JUNIOR, T. O.. The enhanced stream water quality models QUAL2E and QUAL2E-UNCAS: Documentation and user manual. Athens: United States Environmental Protection Agency - U.S.EPA. Environmental Research Laboratory, 1987.

CAMPOS, J. N. B.; STUDART, T. M. C.. Alocação e realocação do direito de uso da água: uma proposta de modelo de marcado limitado no espaço. Revista Brasileira de Recursos Hídricos, Porto Alegre, v.7, p.5-16, 2002. DOI: http://dx.doi.org/10.21168/rbrh.v7n2.p5-16
CHAPRA, S. C.. Surface water quality modeling. 2 ed. New York: McGraw-Hill, 1997.

CHAPRA, S. C.; PELLETIER, G. J.. QUAL2K: a Modeling Framework for simulating river and stream water quality: documentation and user manual. Medford: Civil and environmental Engineering Department, University, 2006.

COX, B. A.. A review of currently available in-stream waterquality models and their applicability for simulating dissolved oxygen in lowland rivers. The Science of the Total Environment, v.314-316, p.303-334, 2003. DOI: http://dx.doi.org/10.1016/s0048-9697(03)00063-9

DROLC, A.; KONCAN, J. Z.. Calibration of QUAL2E model for the Sava River (Slovenia). Water Science and Technology, v.40, p.111-118, 2000

EPA. United States Environmental Protection Agency, Athens. The enhanced stream water quality models QUAL2E and QUAL2E-UNCAS. Documentation and user model. EPA, 1987.

FAN, C.; KO, C.; WANG, W.. An innovative modeling approach using Qual2K and HEC-RAS integration to assess the impact of tidal effect on River Water quality simulation. Journal of Environmental Management, v.90, p.1824-1832, 2009. DOI:

http://dx.doi.org/10.1016/j.jenvman.2008.11.011

FEAM. Plano para Incremento do Percentual de Tratamento de Esgotos Sanitários na Bacia do Rio Piracicaba. Belo Horizonte: FEAM, 2012.

FERRAZ, A. R. G.; BRAGA JUNIOR, B. P. F.. Modelo Decisório para a Outorga de Direito ao Uso da Água no Estado de Sâo Paulo. Revista Brasileira de Recursos Hídricos, Porto Alegre, v.3, p.5-19, 1998. DOI:

http://dx.doi.org/10.21168/rbrh.v3n1.p5-19

FRAGA, M. S.. Modelagem de qualidade da água do rio Piracicaba visando a avaliação de sua capacidade de autodepuração. Dissertação (Mestrado em Engenharia Civil) - Universidade Federal de Viçosa, Viçosa, 2015.

GAZZAZ, N. M.; YUSOFF, M. K.; RAMLI, M. F.; ARIS, A. Z.; JUAHIR, H.. Characterization of spatial patterns in river water quality using chemometric pattern recognition techniques. Marine Pollution Bulletin, v.64, p.688-698, 2012. DOI: http://dx.doi.org/10.1016/j.marpolbul.2012.01.032

GUEDES, H. A. S.. Modelagem da qualidade da água e da capacidade de autodepuração do rio Pomba. Dissertação (Mestrado em Engenharia Civil) - Universidade Federal de Viçosa, Viçosa, 2009.

HIDROTEC. Geração e transferência de tecnologia em recursos hídricos para o Estado de Minas Gerais. 
Universidade Federal de Viçosa, 2014.

JAWORSKA, J. S.; MASSCHELEYN, P.; MCAVOY, D. C.. Application of the QUAL2E Water Quality Model for Untreated Discharge Risk Assessment in Central and Eastern Europe. Assessment and Management of Environmental Risks, v.4, p.163-172, 2001.

KANNEL, P. R.; KANEL, S. R.; LEE, S.; LEE, Y.-S.; GAN, T. Y.. A Review of Public Domain Water Quality Models for Simulating Dissolved Oxygen in Rivers and Streams. Environmental Modeling \& Assessment, v.16, p.183-204, 2011. DOI: https://doi.org/10.1007/s10666-010-9235-1

KELMAN, J.. Gerenciamento de recursos hídricos: outorga e cobrança. In: SIMPÓSIO BRASILEIRO DE RECURSOS HÍDRICOS, 12. Anais. Vitória, 1997.

KNAPIK, H. G.. Reflexões sobre Monitoramento, Modelagem e Calibração na Gestão de Recursos Hídricos: Estudo de caso da Qualidade da Água da Bacia do Alto Iguaçu. Dissertação (Mestrado em Engenharia Ambiental) Universidade Federal do Paraná, 2009.

LISBOA, L.. Sistema para análise das outorgas de captação de água e diluição de efluentes na bacia do Rio Piracicaba MG. Tese (Doutorado em Engenharia Civil) - Universidade Federal de Viçosa, Viçosa, 2014.

MBULIGWE, S. E.; KASEVA, M. E.. Pollution and SelfCleansing of an Urban River in a Developing Country: A Case Study in Dar es Salaam, Tanzania. Environmental Management, v.36, p.328-342, 2005. DOI: https://doi.org/10.1007/s00267-003-0068-4

MENEZES, J. P. C.; BITTENCOURT, R. P.; FARIAS, M. S.; BELLO, I. P.; FIA, R.; OLIVEIRA, L. F. C.. Relação entre padrões de uso e ocupação do solo e qualidade da água em uma bacia hidrográfica urbana. Engenharia Sanitária Ambiental, v.21, p.519-534, 2016. DOI: https://doi.org/10.1590/S141341522016145405

MOURÃO JÚNIOR, P. R.. Aplicação do modelo de autodepuração de qualidade das águas QUAL-UFMG: Estudo de caso sub-bacia do Rio Piracicaba. Dissertação (Mestrado em Engenharia Ambiental) - Universidade Federal de Ouro Preto, Ouro Preto, 2010.

O'CONNOR, D. J.; DOBBINS, W. E.. Mechanism of reaeration in natural streams. Transactions of the American Society of Civil Engineers, v.123, p.641-666, 1958.

PAREDES, J.; ANDREU, J.; SOLERA, A.. A decision support system for water quality issues in the Manzanares River (Spain). Science of the Total Environment, v.408, p.25762589, 2010.

PEREIRA, L. H.; MIRANDA, C. S.; TEODORO, A.; RIBEIRO, M. L.. Estudo da capacidade de autodepuração no córrego Lagoa. In: CONGRESSO BRASILEIRO DE ENGENHARIA SANITÁRIA E AMBIENTAL, 26. Anais. Porto Alegre: ABES, 2011.

PEREIRA, T. V.; MENDONÇA, A. S.. Aplicação de Modelagem Computacional na Simulação de Parâmetros de Qualidade de Água Relacionados com Nitrogênio em Curso d'água. In: SIMPÓSIO BRASILEIRO DE RECURSOS HÍDRICOS, 16. Anais. João Pessoa, 2005.

PIMPUNCHAT, B.; SWEATMAN, W. L.; WAKE, G. C.; TRIAMPO, W.; PARSHOTAM, A.. A mathematical model for pollution in a river and its remediation by aeration. Applied Mathematics Letters, v.22, p.304-308, 2009. DOI: https://doi.org/10.1016/j.aml.2008.03.026

REBOUÇAS, A. C.; BRAGA, B.; TUNDISI, J. G.. Águas doces do Brasil: capital ecológico, uso e conservação. São Paulo: Escrituras, 1999.

REICHERT, P.. AQUASIM 2.0 - Tutorial. Swiss Federal Institute for Environmental Science and Technology, 1998.

SILVA, L. M. C.; MONTEIRO, R. A.. Outorga de Direito de Uso de Recursos Hídricos: uma das possíveis abordagens. In: MACHADO, C. J. S.. Gestão de Águas Doces. Rio de Janeiro, 2004. p.135-178.

SILVA, T. C.; SOUZA, L. L.; CAIADO, M. A. C.; REIS, J. A. T.. Avaliação da capacidade de assimilação de compostos de nitrogênio em rios a partir da aplicação de modelo matemático de qualidade de água. In: CONGRESSO BRASILEIRO DE ENGENHARIA SANITÁRIA E AMBIENTAL, 26. Anais. Porto Alegre: ABES, 2011.

VON SPERLING, M.. Estudos e Modelagem da qualidade da água dos rios. 2 ed. Belo Horizonte: Universidade Federal de Minas Gerais, 2014.

A CBPC - Companhia Brasileira de Produção Científica (CNPJ: 11.221.422/0001-03) detém os direitos materiais desta publicação. Os direitos referem-se à publicação do trabalho em qualquer parte do mundo, incluindo os direitos às renovac̃ões, expansões e disseminações da contribuiç̃o, bem como outros direitos subsidiários. Todos os trabalhos publicados eletronicamente poderão posteriormente ser publicados em coletâneas impressas sob coordenação da Sustenere Publishing, da Companhia Brasileira de Produção Científica e seus parceiros autorizados. Os (as) autores (as) posteriormente ser publicados em coletâneas impressas sob coordenação da Sustenere Publishing, da Companhia Brasileira de Produção Cientifica e seus parce 